\section{Bcl-6 and NF- $\kappa$ B cistromes mediate opposing regulation of the innate immune response}

Grant D. Barish, ${ }^{1}$ Ruth T. Yu, ${ }^{1}$ Malith Karunasiri, ${ }^{1}$ Corinne B. Ocampo, ${ }^{1}$ Jesse Dixon, ${ }^{1}$ Chris Benner, ${ }^{2}$ Alexander L. Dent, ${ }^{3}$ Rajendra K. Tangirala, ${ }^{4}$ and Ronald M. Evans ${ }^{1,5}$

${ }^{1}$ Gene Expression Laboratory, Howard Hughes Medical Institute, The Salk Institute for Biological Studies, La Jolla, California 92037, USA; ${ }^{2}$ Department of Cellular and Molecular Medicine, University of California at San Diego, La Jolla, California 92093, USA; ${ }^{3}$ Department of Microbiology and Immunology, Indiana University School of Medicine, Indianapolis, Indiana 46202, USA; ${ }^{4}$ Division of Endocrinology, Diabetes, and Hypertension, David Geffen School of Medicine, University of California at Los Angeles, Los Angeles, California 90095, USA

In the macrophage, toll-like receptors (TLRs) are key sensors that trigger signaling cascades to activate inflammatory programs via the NF-кB gene network. However, the genomic network targeted by TLR/NF-кB activation and the molecular basis by which it is restrained to terminate activation and re-establish quiescence is poorly understood. Here, using chromatin immunoprecipitation sequencing (ChIP-seq), we define the NF-кB cistrome, which is comprised of 31,070 cis-acting binding sites responsive to lipopolysaccharide (LPS)-induced signaling. In addition, we demonstrate that the transcriptional repressor B-cell lymphoma 6 (Bcl-6) regulates nearly a third of the Tlr4-regulated transcriptome, and that $90 \%$ of the Bcl-6 cistrome is collapsed following Tlr4 activation. Bcl6-deficient macrophages are acutely hypersensitive to LPS and, using comparative ChIP-seq analyses, we found that the Bcl-6 and NF-кB cistromes intersect, within nucleosomal distance, at nearly half of Bcl-6-binding sites in stimulated macrophages to promote opposing epigenetic modifications of the local chromatin. These results reveal a genomic strategy for controlling the innate immune response in which repressive and inductive cistromes establish a dynamic balance between macrophage quiescence and activation via epigenetically marked cis-regulatory elements.

Supplemental material is available for this article.

Received September 30, 2010; revised version accepted October 27, 2010.

Toll-like receptors (TLRs) sense conserved pathogenassociated molecular patterns that rapidly activate the

[Keywords: Bcl-6; NF-кB; macrophage; inflammation, cistrome; ChIP-seq] ${ }^{5}$ Corresponding author.

E-MAIL evans@salk.edu; FAX (858) 455-1349.

Article published online ahead of print. Article and publication date are online at http://www.genesdev.org/cgi/doi/10.1101/gad.1998010. immune system to induce inflammation (Takeuchi and Akira 2010). The transcription factor NF- $\kappa$ B is a common mediator for TLR signaling and is critical for TLR-elicited gene expression programs controlling immune function as well as normal development and tissue homeostasis (Hayden and Ghosh 2004). Growing evidence indicates that TLRs recognize not only microbial products, but also endogenous molecules derived from damaged cells. Underscoring this notion, noninfectious diseases including atherosclerosis, type 2 diabetes mellitus, neurodegeneration, and certain cancers have now been linked to TLRNF- $\mathrm{KB}$ signaling and chronic inflammation (Frantz et al. 2007; Medzhitov 2010). Thus, deciphering the TLR-NF$\kappa \mathrm{B}$ transcriptional network and how it can be controlled is broadly important for understanding immunity as well as disease.

The macrophage is a benign immune sentinel that expresses TLRs and, in response to a range of signals, becomes a principal cellular effector of both acute and chronic inflammation. The tremendous complexity of the TLR-induced inflammatory response, particularly at the level of gene control, has suggested that modular networks demarcate functional pathways and control innate immunity (Medzhitov and Horng 2009). However, the genomic architecture of such networks and the mechanisms by which they are regulated to prevent excessive inflammatory responses are poorly understood. One potential mediator of macrophage quiescence is the sequencespecific transcriptional repressor B-cell lymphoma 6 (BCL-6) (Chang et al. 1996; Dhordain et al. 1997; Huynh and Bardwell 1998; Huynh et al. 2000; Lemercier et al. 2002; Parekh et al. 2007; Mendez et al. 2008). Although best known for its role in B-cell development and nonHodgkin's lymphomas (Dent et al. 1997; Ye et al. 1997), we and others have shown that BCL-6 can bind nuclear receptors and their corepressors, which have been implicated in macrophage modulation of inflammation (Lee et al. 2003; Ogawa et al. 2004; Ghisletti et al. 2009). Moreover, Bcl-6-deficient mice develop lethal neonatal pulmonary vasculitis as well as myocarditis (Dent et al. 1997; Ye et al. 1997) and dysregulated expression of a small number of chemokines and cytokines (Toney et al. 2000; Takeda et al. 2003; Yu et al. 2005; Mondal et al. 2010). These collective observations raised the possibility that Bcl-6 might play a broader role in macrophage quiescence and the termination of the inflammatory response. In this study, we provide genetic and genomic evidence that Bcl-6, acting through a limited number of binding sites, broadly constrains the inflammatory response through cistromic antagonism of a TLR-NF-кB subnetwork.

\section{Results and Discussion}

\section{Bcl-6 controls one-third of the Tlr4 transcriptome}

To begin, we performed genome-wide expression analysis to define the Bcl-6-regulated gene network in quiescent and lipopolysaccharide (LPS)-stimulated Bcl-6 ${ }^{+/+}$(wildtype) and Bcl- $6^{-1-}$ (knockout) bone marrow-derived macrophages (BMDMs). Unexpectedly, a large number of mRNAs (>2500 genes) were altered by the absence of Bcl-6 (Fig. 1A), and $>500$ could be functionally categorized as involved in inflammation $(35 \%)$; differentiation, apoptosis, and cancer $(24 \%)$; cell signaling (12\%); metabolism 
A

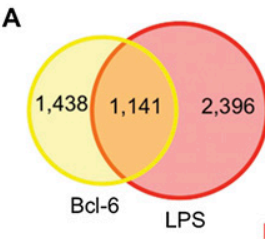

B

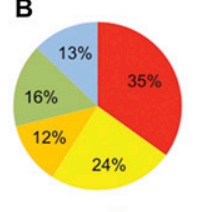

C

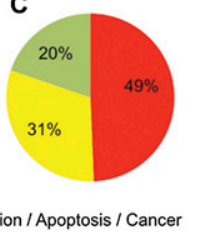

Cell Signaling Metabolism
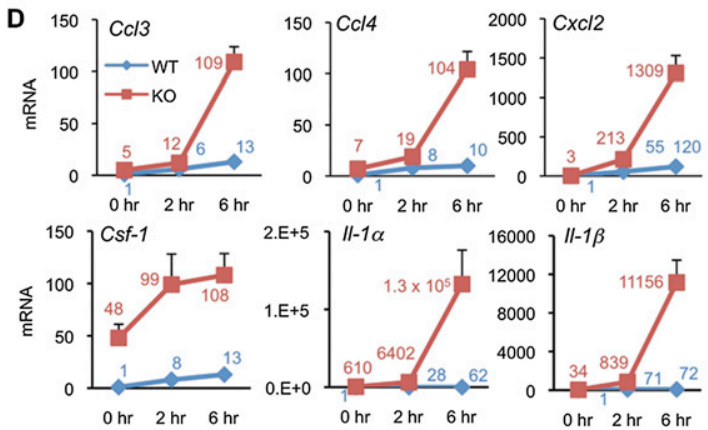
$2 . E+5,11-1 \alpha$
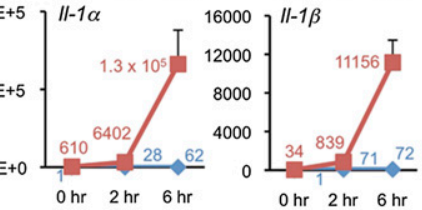

Figure 1. Bcl-6 coregulates the Tlr4-elicited gene expression program. (A) Representation of genes significantly induced or repressed in expression microarrays from wild-type $\left(\mathrm{Bcl}-6^{+++}\right)$and knockout $\left(\mathrm{Bcl}-6^{-1-}\right)$ BMDMs versus genes significantly altered in wild-type BMDMs by exposure to LPS $(100 \mathrm{ng} / \mathrm{mL})$ for $6 \mathrm{~h} .(B, C)$ Functional categorization of Bcl-6-regulated genes $(B)$ or Bcl-6- and LPS-coregulated genes $(C)$ depicted as percentages of total. $(D)$ qPCR of microarray-identified Bcl-6- and LPS-coregulated genes in wild-type and knockout BMDMs at 0, 2, or $6 \mathrm{~h}$ following exposure to LPS (100 ng/ $\mathrm{mL})$. The mean relative expression $\pm \mathrm{SD}$ compared with wild-type BMDMs at baseline $(0 \mathrm{~h})$ is listed.

$(16 \%)$; or other assorted pathways (13\%) (Fig. 1B; Supplemental Table 1). Treatment with the inflammatory trigger LPS resulted in vast changes in the expression of $>3500$ genes in either wild-type or knockout cells (Fig. 1A; Supplemental Fig. 1A). Remarkably, comparison of these gene networks revealed that more than a third of the LPS-elicited transcriptome is also controlled by Bcl-6 (Fig. 1A), and, for $>60 \%$ of these coregulated genes, loss of Bcl-6 mimicked LPS stimulation. Analysis of Bcl-6- and LPS-coregulated genes found that nearly half of those classified were inflammatory (Fig. 1C; Supplemental Table 2). Using quantitative PCR (qPCR), we interrogated many of these targets in wild-type and knockout BMDMs over a 6-h time course of LPS exposure, demonstrating that loss of Bcl-6 produces a broad and often striking hypersensitive response (Fig. 1D; Supplemental Fig. 1B). Among the many dramatically coregulated genes were an array of C-C and C-X-C chemokines involved in inflammatory cell recruitment (Charo and Ransohoff 2006), including Ccl-2, Ccl-3, Ccl-4, and Ccl-7, as well as Cxcl2, Cxcl-11, and Cxcl-14; growth factors such as Csf-1, which drives leukocyte chemotaxis, differentiation, and proliferation (Pixley and Stanley 2004); acute phase cytokines (e.g., Il-1 $\alpha$ and Il-1 $\beta$ ); and anti-inflammatory modulators, including Ppary and Dusp1 (Jeffrey et al. 2007). Many of these genes showed striking changes in basal expression that were amplified further by LPS treatment. For example, Il-1 $\alpha$ showed a 610-fold elevation of basal expression and, after LPS stimulation was induced, 130,000-fold in knockout versus unstimulated wild-type cells. This dramatic LPS induction in Bcl-6-deficient cells exceeded the maximal LPS-stimulated expression of $I l-1 \alpha$ in wild-type cells by more than three orders of magnitude. Variant but related, exaggerated patterns were observed among many other inflammatory genes, with a few exceptions (such as Ccl6) where no discernable impact of LPS stimulation was seen (Fig. 1D; Supplemental Fig. 1B). These results reveal that Bcl-6 prevents a hyperinflammatory response by controlling transcriptional modules both within and outside of the LPS-induced transcriptome. Within the Tlr4 network, Bcl-6 controls approximately one-third of the transcriptome, where it additionally helps to suppress basal transcription to establish the quiescent state.

Not all Tlr4-regulated genes are proinflammatory, as exemplified by Bcl-6 itself, whose transient induction within $2 \mathrm{~h}$ following LPS exposure (Supplemental Fig. $1 \mathrm{C}, \mathrm{D})$ presumably helps to attenuate the LPS response to prevent nonresolving inflammation. Using Bcl-6 regulation as a model, BMDMs were treated with TLR signaling inhibitors (including Mek1 and Mek2 [U0126], Erk 1/2 [ErkII inhibitor], PI3 kinase [wortmannin], and NF-кB [Bay 11-7082]) to deconstruct the regulatory cascade. LPS induction of Bcl-6 and Ccl2 was completely attenuated by Bay 11-7082 (Supplemental Fig. 1E), suggesting that NF- $\kappa$ B contributes to both induction and feedback inhibition of the Tlr4-induced transcriptional response.

\section{The dynamic Bcl-6 cistrome}

We next wished to understand the chromatin basis of Bcl-6 regulation, and performed genome-wide binding location analysis in wild-type BMDMs using chromatin immunoprecipitation sequencing (ChIP-seq). The resulting cistrome identified 6655 Bcl-6 interaction sites in unstimulated cells (Fig. 2A). Their complete loss in Bcl$6^{-1-}$ cells confirmed the identity of the sites as well as the specificity of the antibody (Supplemental Fig. 2A). Surprisingly, the vast majority of Bcl-6 binding localizes to distant intergenic and intronic sites, with only $5 \%$ occurring at gene promoters (Fig. 2A; Supplemental Fig. 2B). Nearby gene annotation analysis assigned peaks based on their proximity to the closest transcription start site, yielding a total of 4354 genes within the unstimulated Bcl-6 cistrome (Fig. 2B). Gene ontology analysis revealed that the most common classified function for annotated genes was inflammatory (28\%) (Fig. 2C; Supplemental Table 3). Because transcription factors can act directly as well as by long-range or indirect mechanisms, we compared the gene sets identified by expression microarray and ChIP-seq (Fig. 2B). Interestingly, of the genes whose basal expression was altered in knockout macrophages, about a third were found to have Bcl-6-binding sites, suggesting that loss of Bcl-6 often amplifies to noncistromic genes. Moreover, for many genes with Bcl-6-binding sites, the loss of Bcl-6 did not substantially impact basal gene expression, implicating probable additional roles in activated macrophages.

Motif analysis performed on the Bcl-6 ChIP-sequenced DNA identified canonical Bcl-6 consensus binding sites within $74 \%$ of binding peaks in quiescent BMDMs (Supplemental Fig. 2D). Interestingly, motifs for the critical myeloid lineage and enhancer factor Pu.1 (Scott et al. 1994; Ghisletti et al. 2010; Heinz et al. 2010) were the next most common (Supplemental Fig. 2D), implying that Bcl-6 establishes quiescence in part by actively repressing proximal Pu.1-marked enhancers. To test these predictions, we additionally ChIP-sequenced Pu. 1 and p300, dual 
A

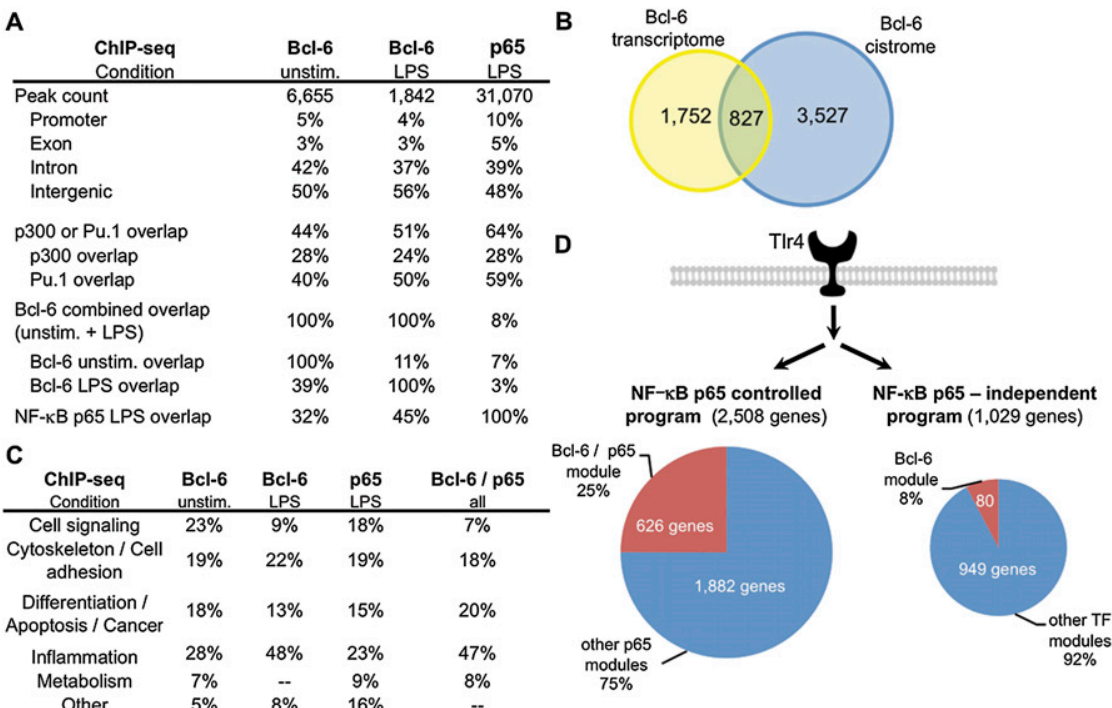

Figure 2. ChIP-seq reveals extensive colocalization of Bcl-6 with NF-кB. $(A)$ Distribution of Bcl-6 and NF-кB p65-binding sites in BMDMs and their overlap with other cistromes as indicated. $(B)$ Graphical depiction of the number of genes identified with significantly altered expression in Bcl-6 $6^{-1-}$ versus Bcl- $6^{+/+}$BMDMs (yellow), the number of genes annotated with Bcl-6-binding sites by ChIP-seq (blue), and the intersections of these gene sets in unstimulated BMDMs. $(C)$ Functional classification of genes identified with binding sites for Bcl-6, NF- $\mathrm{kB}$ or proximal Bcl-6 and NF-кB by ChIP-seq in unstimulated and LPS-stimulated BMDMs. $(D$ Schematic representing Tlr4-initiated transcriptional programs that are NF- $\mathrm{kB}$ p65-controlled (left) and NF-кB p65-independent (right) based on p65 ChIP-seq annotation. (Left) Bcl-6 regulation of Tlr4 responses is concentrated in genes annotated with proximal Bcl-6 and NF- $\mathrm{kB}$ sites. (Right) Bcl-6 binding is infrequent in Tlr4 target genes controlled by other transcription factors (TFs).

signatures for macrophage enhancers /Ghisletti et al. 2010), and found that Pu.1 and/or p300 co-occur at $>44 \%$ of Bcl-6-binding sites in unstimulated cells (Fig. 2A). Surprisingly, binding motifs for NF-кB were also highly enriched in Bcl-6 ChIP-sequenced DNA (Supplemental Fig. 2D), raising the possibility that Bcl-6 intersects with a canonical inflammatory signaling pathway.

To explore the impact of inflammatory stimulation on Bcl-6-directed genomic regulation, we ChIP-sequenced Bcl-6 in BMDMs treated with LPS for $3 \mathrm{~h}$, at which time Bcl-6 protein is maximal (Supplemental Fig. 1D). Two unexpected, rapid, and dynamic changes occurred. First, the "quiescent" Bcl-6 cistrome was reduced nearly $90 \%$ to 726 residual sites, and second, stimulation induced an additional 1116 "LPS-specific" sites (Fig. 2A). The induced Bcl-6 cistrome of 1842 sites was particularly concentrated in genes controlling inflammatory responses $(48 \%)$ as well as cell adhesion and migration (22\%) (Fig. $2 \mathrm{C}$; Supplemental Table 4). In exploring the dynamic shift in the Bcl-6 cistrome, a 12-h kinetic analysis of Bcl-6 using ChIP qPCR of LPS-exposed BMDMs (Supplemental Fig. 2F) confirmed that binding was transiently lost (e.g., Csf1), retained (e.g., Ccl2), or gained (e.g., Ifitm1) over the course of LPS stimulation. Previous work suggests that signal-induced acetylation and phosphorylation of the Bcl-6 protein diminish its DNA binding and stability, potentially contributing to these LPS-triggered binding dynamics (Niu et al. 1998; Bereshchenko et al. 2002; Barros et al. 2009). The general distribution of the Bcl-6 cistrome in LPS-stimulated BMDMs at promoters, exons, introns, and intergenic sites mirrored the coverage in unstimulated cells and likewise often colocalized with
Pu. 1 and p300 at presumptive enhancers (Fig. 2A). These results indicate that the Bcl-6 cistrome is highly dynamic and signal-dependent, and its capacity to transform may underpin the rapid genomic response to an inflammatory trigger.

\section{Bcl-6-NF- $\mathrm{B}$ cistromic antagonism}

In considering the dynamic nature of the Bcl-6 cistrome, our attention returned to the potential intersection with NF- $\kappa \mathrm{B}$ and the possibility of reciprocal regulation by overlapping cistromes. In support of this idea, motif analysis of Bcl-6 ChIP-sequenced DNA in LPS-stimulated BMDMs, as in quiescent macrophages, identified NF-кB consensus motifs among the top scoring, along with motifs for Bcl-6 itself and the myeloid pioneering factor Pu.1 (Supplemental Fig. 2E). To examine the potential for "genomic cross-talk," we first needed to establish the NF-кB cistrome. Using p65 as the hallmark of the active NF-кB complex, only 164 binding sites were found in quiescent BMDMs, presumably due to cytoplasmic sequestration in unstimulated cells. Nevertheless, NF-кB motifs were the most abundant in the ChIP-sequenced DNA (Supplemental Fig. 3A). Impressively, while LPS treatment considerably reduced the Bcl- 6 cistrome, it reciprocally increased NF-кB binding to $>31,000$ peaks (Fig. 2A), which were heavily enriched with motifs for NF- $\mathrm{BB}$ and Pu.1 (Supplemental Fig. 3B). As with Bcl-6, NF-кB localized predominantly to promoter-distal sites, with promoter binding comprising only $10 \%$ of its cistrome (Fig. 2A). Consistent with its breadth of functions in immunity as well as development and homeostasis (Hayden and Ghosh 2004), genes annotated with ChIP-seq-identified NF-кB-binding sites were widely distributed among functional pathways related to inflammation (23\%); the cytoskeleton and cell adhesion (19\%); cell signaling (18\%); differentiation, apoptosis, and cancer $(15 \%)$; metabolism $(9 \%)$; and other assorted functions $(16 \%)$ (Fig. $2 \mathrm{C})$. The regulatory relationship between NF-кB and Bcl-6 was further revealed as we examined the Bcl-6 gene itself. Following LPS stimulation, p65 binding appeared in a distributed fashion over a region of $50 \mathrm{~kb}$ within and flanking the Bcl-6 gene, confirming that Bcl-6 is a directly regulated NF- $\mathrm{kB}$ target (Supplemental Fig. 3C). Bcl-6 thus is both a basal and inducible inhibitor to oppose NF-кB-directed regulation.

In further exploring aspects of Bcl-6 and NF- $\mathrm{B}$ reciprocal regulation, we observed that thousands of NF-кB and Bcl-6 sites colocalized to within a nucleosomal window (200 base pairs) with a total of 2422 sites of cooccurrent binding by Bcl-6 and NF-кB (Supplemental Fig. 3D). These Bcl-6/p65 sites represent $45 \%$ and $32 \%$ of the Bcl-6 stimulated or quiescent cistromes, respectively (Fig. 2A). Although combined this represents only $8 \%$ of the NF- $\kappa$ B cistrome (Fig. 2A), the Bcl-6/p65 nucleosome module appears particularly important for the LPS transcriptional program. Since NF-кB p65 is a critical transcriptional 
mediator for Tlr4 signals, we compared genes annotated with p65-binding sites based on our ChIP-seq data to genes whose expression was altered by LPS. NF- $\kappa$ B p 65 annotated to $>70 \%$ of genes induced or repressed by LPS stimulation (Fig. 2D). Surprisingly, the Bcl-6/ p65 module was heavily overrepresented in differentially expressed LPS targets (626 genes) (Fig. 2D, left), particularly among those that were induced by LPS. In contrast, only a small portion (80 genes) of the NF-кB-independent Tlr4-directed gene program contained assignable Bcl-6-binding sites (Fig. 2D, right). Thus, although Bcl-6/p65 sites account for just $8 \%$ of the NF-кB p65 cistrome (Fig. 2A; Supplemental Fig. 3D), Bcl-6/p65 sites occur in $25 \%$ of the Tlr4-NF-кB controlled gene network and overall span $18 \%$ of Tlr4 response genes (Fig. 2D). Importantly, functional analysis of the Bcl-6/NF- $\mathrm{B}$ module revealed genes that were particularly enriched among inflammatory pathways $(47 \%)$ (Fig. 2C). Thus, the substantial proximal convergence between Bcl-6 and NF-кB suggested that cistromic overlap may be an effective way for Bcl-6 to limit the extent of the NF-кB-directed macrophage inflammatory response. Interestingly, BCL-6 has also been reported to inhibit NF- $\mathrm{B}$ activity in diffuse large B-cell lymphomas, raising the possibility that Bcl-6-NF- $\mathrm{B}$ cistromic antagonism may be important in other cell types (Perez-Rosado et al. 2008).

The basis of the proposed cistromic antagonism was further illustrated by examining its potential impact along key inflammatory target genes, including the Il-1 (Fig. 3A) and $\mathrm{Ccl} 2 / \mathrm{Ccl} 7 / \mathrm{Ccl11}$ (Supplemental Fig. 4A) gene clusters. Visualization of these sequencing tracks demonstrated that, in the absence of stimulation, Bcl-6 forms a colocalization nexus with multiple factors and histone marks characteristic for macrophage enhancers, including Pu.1, p300, RNA polymerase II (pol II), monomethylated $\mathrm{H} 3 \mathrm{~K} 4$, and islands of histone acetylation (Heintzman et al. 2007; Visel et al. 2009; Ghisletti et al. 2010; Heinz et al. 2010), whereas NF-кB p65 was minimally detectable. Following $3 \mathrm{~h}$ of LPS stimulation, robust NF-кB occupancy was detected along Pu.1-marked enhancers, and p300 was likewise inducibly recruited to many (i.e., Il-1 $\alpha$ ) (Fig 3A), but not all NF-кB-binding sites (i.e., Ccl2) (Supplemental Fig. 4A). ChIP qPCR analysis revealed similar p65 and p300 occupancy in either wild-type or knockout cells (Supplemental Fig. 4B,C). Alternatively, Bcl-6 was variably reduced but not entirely lost along these genes following LPS exposure (Fig. 3A; Supplemental Fig. 4A). Together, these findings suggest that Bcl-6 and NF-кB function by proximal binding to enhancer regions, where they are reciprocally diminished or enhanced, respectively, upon Tlr4 stimulation.

Next, we explored the epigenetic implications of Bcl-6 and NF- $\kappa \mathrm{B}$ antagonism by comparing the status of $\mathrm{H} 3 \mathrm{~K} 4$ monomethylation and $\mathrm{H} 3$ acetylation as well as the recruitment of histone-modifying factors to Bcl-6/p65binding sites in wild-type and knockout BMDMs. H3K4 monomethylation, a signature mark of enhancers, was minimally impacted by the presence of Bcl-6 or LPS stimulation (Supplemental Fig. 5A,B). In contrast, ChIP qPCR demonstrated that loss of Bcl- 6 caused consistent hyperacetylation at these sites (Fig. 3B; Supplemental Fig. $5 \mathrm{C}$, orange and red columns). Following LPS exposure, we also observed significant losses of histones H3 and H4 near cytokine genes in wild-type and knockout BMDMs (Supplemental Fig. 5D; data not shown). These observations suggest that acute activation may promote nucleosome destabilization at Bcl-6/p65-binding sites along enhancers, similar to the TLR-induced remodeling observed at other sites (Ramirez-Carrozzi et al. 2006). Accordingly, we found an increased density of acetylated $\mathrm{H} 3$ at Bcl-6/p65 sites in knockout BMDMs, and particularly, although not universally, in knockout cells stimulated with LPS (e.g., Il-1- and Il-6-binding sites) (Fig. 3B). Mirroring these changes in acetylation, LPS exposure caused the histone acetyltransferase p300 to inducibly bind in the vicinity of many inflammatory genes (Supplemental Fig. 4C). Opposing this enzymatic activity, Hdac3, but not Hdac1 or Hdac2, was found to occur at Bcl-6/NF-кB-binding sites in a Bcl-6-dependent manner and was enhanced by LPS stimulation (Fig. 3C; data not 


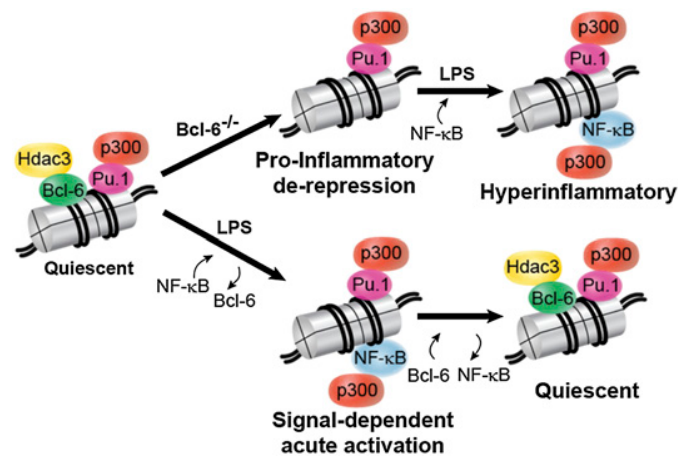

Figure 4. Model of macrophage Bcl-6 in inflammatory control. Bcl-6 restrains inflammation through transcriptional repression via histone deacetylation at inflammatory gene enhancers, in close proximity to sites inducibly bound by NF-кB and the histone acetyltransferase p300 following Tlr4 stimulation. In the setting of TLR signals, loss of Bcl-6 and its corepressor, Hdac3, results in unopposed NF-kB transcriptional activation and hyperinflammatory responses.

shown). Together, these findings suggest that the Bcl6-repressive module restricts NF-кB and p300 activation by limiting basal and Tlr-inducible histone acetylation.

Defining the genetic mechanisms that maintain inflammatory genes in a responsive but repressed state under normal conditions or resolve an acute inflammatory response is key to identifying checkpoints in the innate immune response, as well as devising new approaches to treat inflammatory disease. Here, we identify a previously unknown yet integral role for the transcriptional repressor Bcl-6 in maintaining macrophage quiescence and restricting the intensity of the inflammatory response by cistrome-based antagonism of NF-кB. Both the Bcl-6-repressive and NF-кB-activating cistromes are dynamic, with Bcl-6 loss resulting in proinflammatory derepression and hypersensitivity to LPS stimulation via loss of Hdac3 and unopposed p300 activity (Fig. 4, upper pathway). These findings suggest that a dynamic balance between NF- $\mathrm{KB}$ and Bcl-6 cistromes is used to regulate the innate immune response by colocalizing opposing epigenetic regulators to shared nucleosomal domains (Fig. 4, lower pathway).

\section{Materials and methods}

\section{Primary macrophage differentiation and cell culture}

All cells were from mice with an isogenic C57 background. Macrophage differentiation is described elsewhere (Barish et al. 2005).

\section{Immunoblotting and gene expression}

Immunoblotting, RNA extraction, and qPCR were performed as described previously (Barish et al. 2005). Relative protein concentration was determined using a Bio-Rad ChemiDoc and ImageLab software. Primers for gene expression are in Supplemental Table 7. Microarrays were performed with Illumina BeadChips. See the Supplemental Material for details.

\section{ChIP and ChIP-seq}

ChIP assays were performed as described elsewhere (Nelson et al. 2006) with modifications. See the Supplemental Material for details. ChIP qPCR assays were performed using biological triplicates with primers listed in Supplemental Table 8. For ChIP-seq, chromatin-antibody complexes were precipitated with anti-IgG paramagnetic beads (Invitrogen). Libraries were made per manufacturer instructions and sequenced using an Illumina Genome Analyzer II. Analysis is described in the Supplemental Material.

\section{Acknowledgments}

We thank E. Ong and S. Ganley for administrative assistance; E. Grabowski for graphic artwork; J. Ecker, R. Lister, and J. Nery for assistance with DNA sequencing (Salk Institute for Biological Studies); C. Glass (University of California at San Diegol for assistance with HOMER ChIP-seq analysis software; and A. Melnick (Weill Cornell Medical College) for helpful discussion. This work was funded by NIH grants 1K08HL092298 (to G.D.B.), P01HL088093 (to R.M.E.), U19DK062434 (to R.M.E.), R37DK057978 (to R.M.E.), R01HD027183 (to R.M.E.), R01HL086566 (to R.K.T.), and P30DK063491/DERC (to R.K.T.), and support from Dr. Alan Fogelman and the David Geffen School of Medicine at University of California at Los Angeles (to R.K.T.), the Samuel Waxman Cancer Research Foundation (to R.M.E.), the Chapman Foundation (to R.M.E.), and Howard Hughes Medical Institute (to R.M.E.). R.M.E. is an investigator of the Howard Hughes Medical Institute and March of Dimes Chair in Molecular and Developmental Biology at the Salk Institute for Biological Studies.

\section{References}

Barish GD, Downes M, Alaynick WA, Yu RT, Ocampo CB, Bookout AL, Mangelsdorf DJ, Evans RM. 2005. A nuclear receptor atlas: Macrophage activation. Mol Endocrinol 19: 2466-2477.

Barros P, Jordan P, Matos P. 2009. Rac1 signaling modulates BCL-6mediated repression of gene transcription. Mol Cell Biol 29: 4156-4166.

Bereshchenko OR, Gu W, Dalla-Favera R. 2002. Acetylation inactivates the transcriptional repressor BCL6. Nat Genet 32: 606-613.

Chang CC, Ye BH, Chaganti RS, Dalla-Favera R. 1996. BCL-6, a POZ/ zinc-finger protein, is a sequence-specific transcriptional repressor. Proc Natl Acad Sci 93: 6947-6952.

Charo IF, Ransohoff RM. 2006. The many roles of chemokines and chemokine receptors in inflammation. N Eng1 J Med 354: 610-621.

Dent AL, Shaffer AL, Yu X, Allman D, Staudt LM. 1997. Control of inflammation, cytokine expression, and germinal center formation by BCL-6. Science 276: 589-592.

Dhordain P, Albagli O, Lin RJ, Ansieau S, Quief S, Leutz A, Kerckaert JP, Evans RM, Leprince D. 1997. Corepressor SMRT binds the BTB/POZ repressing domain of the LAZ3/BCL6 oncoprotein. Proc Nat1 Acad Sci 94: 10762-10767.

Frantz S, Ertl G, Bauersachs J. 2007. Mechanisms of disease: Toll-like receptors in cardiovascular disease. Nat Clin Pract Cardiovasc Med 4: 444-454.

Ghisletti S, Huang W, Jepsen K, Benner C, Hardiman G, Rosenfeld MG, Glass CK. 2009. Cooperative NCoR/SMRT interactions establish a corepressor-based strategy for integration of inflammatory and anti-inflammatory signaling pathways. Genes Dev 23: 681-693.

Ghisletti S, Barozzi I, Mietton F, Polletti S, De Santa F, Venturini E, Gregory L, Lonie L, Chew A, Wei CL, et al. 2010. Identification and characterization of enhancers controlling the inflammatory gene expression program in macrophages. Immunity 32: 317-328.

Hayden MS, Ghosh S. 2004. Signaling to NF-кB. Genes Dev 18: 21952224.

Heintzman ND, Stuart RK, Hon G, Fu Y, Ching CW, Hawkins RD, Barrera LO, Van Calcar S, Qu C, Ching KA, et al. 2007. Distinct and predictive chromatin signatures of transcriptional promoters and enhancers in the human genome. Nat Genet 39: 311-318.

Heinz S, Benner C, Spann N, Bertolino E, Lin YC, Laslo P, Cheng JX, Murre C, Singh H, Glass CK. 2010. Simple combinations of lineagedetermining transcription factors prime cis-regulatory elements required for macrophage and B cell identities. Mol Cell 38: 576-589.

Huynh KD, Bardwell VJ. 1998. The BCL-6 POZ domain and other POZ domains interact with the co-repressors N-CoR and SMRT. Oncogene 17: $2473-2484$

Huynh KD, Fischle W, Verdin E, Bardwell VJ. 2000. BCoR, a novel corepressor involved in BCL-6 repression. Genes Dev 14: 1810-1823.

Jeffrey K, Camps M, Rommel C, Mackay C. 2007. Targeting dualspecificity phosphatases: Manipulating MAP kinase signalling and immune responses. Nat Rev Drug Discov 6: 391-403. 
Lee CH, Chawla A, Urbiztondo N, Liao D, Boisvert WA, Evans RM, Curtiss LK. 2003. Transcriptional repression of atherogenic inflammation: Modulation by PPARס. Science 302: 453-457.

Lemercier C, Brocard MP, Puvion-Dutilleul F, Kao HY, Albagli O, Khochbin S. 2002. Class II histone deacetylases are directly recruited by BCL6 transcriptional repressor. J Biol Chem 277: 22045-22052.

Medzhitov R. 2010. Inflammation 2010: New adventures of an old flame. Cell 140: 771-776.

Medzhitov R, Horng T. 2009. Transcriptional control of the inflammatory response. Nat Rev Immunol 9: 692-703.

Mendez LM, Polo JM, Yu JJ, Krupski M, Ding BB, Melnick A, Ye BH. 2008. CtBP is an essential corepressor for BCL6 autoregulation. Mol Cell Biol 28: 2175-2186.

Mondal A, Sawant D, Dent AL. 2010. Transcriptional repressor BCL6 controls Th17 responses by controlling gene expression in both $\mathrm{T}$ cells and macrophages. J Immunol 184: 4123-4132.

Nelson JD, Denisenko O, Bomsztyk K. 2006. Protocol for the fast chromatin immunoprecipitation (ChIP) method. Nat Protoc 1: 179185.

Niu H, Ye BH, Dalla-Favera R. 1998. Antigen receptor signaling induces MAP kinase-mediated phosphorylation and degradation of the BCL-6 transcription factor. Genes Dev 12: 1953-1961.

Ogawa S, Lozach J, Jepsen K, Sawka-Verhelle D, Perissi V, Sasik R, Rose DW, Johnson RS, Rosenfeld MG, Glass CK. 2004. A nuclear receptor corepressor transcriptional checkpoint controlling activator protein 1-dependent gene networks required for macrophage activation. Proc Natl Acad Sci 101: 14461-14466.

Parekh S, Polo JM, Shaknovich R, Juszczynski P, Lev P, Ranuncolo SM, Yin Y, Klein U, Cattoretti G, Dalla Favera R, et al. 2007. BCL6 programs lymphoma cells for survival and differentiation through distinct biochemical mechanisms. Blood 110: 2067-2074.

Perez-Rosado A, Artiga M, Vargiu P, Sanchez-Aguilera A, AlvarezBarrientos A, Piris M. 2008. BCL6 represses NFkB activity in diffuse large B-cell lymphomas. J Pathol 214: 498-507.

Pixley FJ, Stanley ER. 2004. CSF-1 regulation of the wandering macrophage: Complexity in action. Trends Cell Biol 14: 628-638.

Ramirez-Carrozzi VR, Nazarian AA, Li CC, Gore SL, Sridharan R, Imbalzano AN, Smale ST. 2006. Selective and antagonistic functions of SWI/SNF and Mi-2 $\beta$ nucleosome remodeling complexes during an inflammatory response. Genes Dev 20: 282-296.

Scott EW, Simon MC, Anastasi J, Singh H. 1994. Requirement of transcription factor PU.1 in the development of multiple hematopoietic lineages. Science 265: 1573-1577.

Takeda N, Arima M, Tsuruoka N, Okada S, Hatano M, Sakamoto A, Kohno Y, Tokuhisa T. 2003. Bcl6 is a transcriptional repressor for the IL-18 gene. J Immunol 171: 426-431.

Takeuchi O, Akira S. 2010. Pattern recognition receptors and inflammation. Cell 140: 805-820.

Toney L, Cattoretti G, Graf J, Merghoub T, Pandolfi P, Dalla-Favera R, Ye B, Dent A. 2000. BCL-6 regulates chemokine gene transcription in macrophages. Nat Immunol 1: 214-220.

Visel A, Blow MJ, Li Z, Zhang T, Akiyama JA, Holt A, Plajzer-Frick I, Shoukry M, Wright C, Chen F, et al. 2009. ChIP-seq accurately predicts tissue-specific activity of enhancers. Nature 457: 854-858.

Ye BH, Cattoretti G, Shen Q, Zhang J, Hawe N, de Waard R, Leung C, Nouri-Shirazi M, Orazi A, Chaganti RS, et al. 1997. The BCL-6 protooncogene controls germinal-centre formation and Th2-type inflammation. Nat Genet 16: 161-170.

Yu RY, Wang X, Pixley FJ, Yu JJ, Dent AL, Broxmeyer HE, Stanley ER, Ye BH. 2005. BCL-6 negatively regulates macrophage proliferation by suppressing autocrine IL-6 production. Blood 105: 1777-1784. 


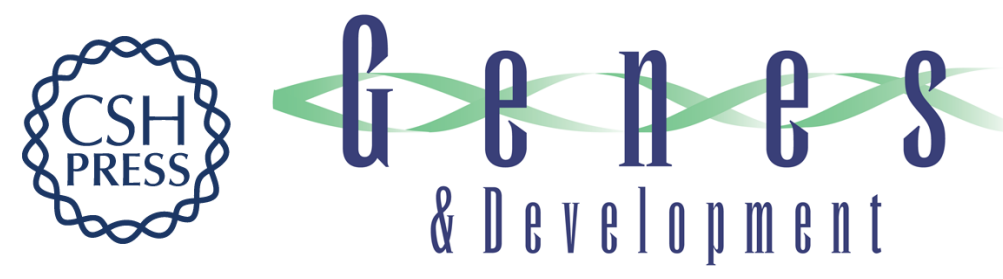

\section{Bcl-6 and NF- $\kappa$ B cistromes mediate opposing regulation of the innate immune response}

Grant D. Barish, Ruth T. Yu, Malith Karunasiri, et al.

Genes Dev. 2010, 24: originally published online November 24, 2010

Access the most recent version at doi:10.1101/gad.1998010

\section{Supplemental http://genesdev.cshlp.org/content/suppl/2010/11/18/gad.1998010.DC1 Material}

References This article cites 36 articles, 18 of which can be accessed free at: http://genesdev.cshlp.org/content/24/24/2760.full.html\#ref-list-1

\section{License}

Email Alerting

Receive free email alerts when new articles cite this article - sign up in the box at the top Service 